\title{
Процессы самосборки нанокристаллов CdS, синтезированных методом Ленгмюра-Блоджетт
}

\author{
(С) К.А. Свит ${ }^{1}$, К.С. Журавлев ${ }^{1,2}$ \\ ${ }^{1}$ Институт фризики полупроводников им. А.В. Ржанова Сибирского отделения Российской академии наук, \\ 630090 Новосибирск, Россия \\ ${ }^{2}$ Новосибирский государственный университет, \\ 630090 Новосибирск, Россия \\ E-mail: svit@isp.ncs.ru, k.zhuravlev@nsu.ru
}

Поступила в Редакцию 22 апреля 2019 г.

В окончательной редакции 28 апреля 2019 г.

Принята к публикации 28 апреля 2019 г.

\begin{abstract}
Методом атомно-силовой микроскопии исследована морфология массивов нанокристаллов $\mathrm{CdS}$, самособранных в процессе испарения органической матрицы бегеновой кислоты, на поверхности смачиваемой подложки. Исследована зависимость морфологии массивов нанокристаллов от толщины исходной матрицы. Морфология массивов нанокристаллов заметно меняется от мелких фрактальных массивов до пористого субмонослоя по мере повышения плотности нанокристаллов. Предложена природа сил отталкивания между нанокристаллами, которая препятствует их необратимому слипанию и обеспечивает их сравнительно высокую подвижность в составе массивов.
\end{abstract}

Ключевые слова: сульфид кадмия, нанокристаллы, самосборка, метод Ленгмюра-Блоджетт.

DOI: 10.21883/FTP.2019.11.48458.9144

\section{1. Введение}

Полупроводниковые нанокристаллы (НК) привлекают к себе внимание исследователей уже на протяжении нескольких десятилетий. Основным достоинством НК в сравнении с объемным материалом является возможность контролировать их энергетический спектр путем варьирования их формы, размера и состояния поверхности [1-3]. Благодаря таким уникальным свойствам НК имеют широкие перспективы применения в медицине, электронике и оптике [4]. Дополнительный интерес исследователей вызывают физические явления в массивах НК, в частности коллективные явления, которые связаны с взаимодействием НК в составе массивов [5]. В связи с тем, что большинство практических применений НК, например, в качестве люминофора в жидкокристаллических дисплеях, рассчитано на использование массивов НК, становится актуальной проблема создания массивов с требуемой конфигурацией на подложках из различных материалов.

Процесс самосборки НК наиболее широко изучался в коллоидных системах [6]. Множество работ по изучению данного процесса в коллоидных системах позволило установить, что морфология массивов НК зависит от множества факторов, среди которых можно выделить тип и величину сил взаимодействия между НК, а также между НК и подложкой, смачиваемость подложки и капиллярные эффекты [7-9]. В зависимости от преобладания того или иного фактора возможно получить массивы НК различных конфигураций: двумерные монослойные массивы, трехмерные плотноупакованные массив НК и более сложные структуры [10-12]. Тем не менее коллоидные НК и их массивы имеют ряд недостатков, которые ограничивают их применение. Первым недостатком является наличие у коллоидных НК оболочки из органических лигандов. Данная оболочка необходима при синтезе НК для предотвращения процессов агрегации в растворе, пассивирует их поверхность. Органическая оболочка имеет сравнительно большую толщину, связанную с длиной молекул, покрывающих поверхность НК, вследствие чего минимальное расстояние между НК в массиве ограничено. Ограничение на минимальное расстояние между НК ведет за собой ограничение на их взаимодействие, что наиболее критично в таких эффектах, как перенос заряда и энергии между НК в массиве, и усложняет получение массивов НК с ярковыраженными коллективными свойствами [13]. Вторым недостатком коллоидных НК является то, что для их дальнейшего равномерного нанесения на подложку, как правило, требуется операция центрифугирования, которая создает технологические проблемы на подложках большой площади.

Альтернативой коллоидным НК являются нанокристаллы, синтезированные с помощью метода Ленгмюра-Блоджетт (ЛБ) [14]. Данная методика заключается в нанесении на подложку методом ЛБ матрицы жирной кислоты необходимой толщины, синтезе НК в данной матрице и дальнейшем удалении матрицы для получения свободностоящих НК. Данная методика не требует наличия у НК органической оболочки, а для пассивации поверхности НК используются молекулы газа - например, аммиака в случае НК из полупроводников группы $\mathrm{A}^{\mathrm{II}} \mathrm{B}^{\mathrm{VI}}$. Молекулы газа имеют меньший размер относительно органических лигандов, что позволяет сократить расстояние между соседними НК в массиве и увеличить их взаимодействие. Например, длины молекул 
одних из наиболее популярных органических лигандов, таких как олеиновая кислота и оксид триоктилфосфина, составляют 1.8 и 1.3 нм соответственно, в то время как размер молекулы аммиака $\sim 0.5$ нм. Кроме того, метод ЛБ легко масштабируем, что позволяет наносить органическую матрицу на подложки большой площади и сложной формы с монослойной точностью. Несмотря на преимущества данного метода, формирование массивов НК в процессе удаления органической матрицы слабо изучены. Ряд пионерских работ показал принципиальную возможность создания массивов НК, синтезированных с помощью данного метода, однако сами механизмы самосборки не изучены $[15,16]$.

Целью данной работы является изучение механизмов самосборки при формировании массивов $\mathrm{HK} \mathrm{CdS}$, синтезированных с помощью метода ЛБ, в процессе испарения органической матрицы на поверхности высокоориентированного пиролитического графита (ВОПГ).

\section{2. Методика эксперимента}

Нанокристаллы CdS были синтезированы с помощью метода ЛБ в матрице бегеновой кислоты. В качестве подложки использовался ВОПГ, так как он имеет низкую шероховатость поверхности и хорошо смачивается материалом матрицы, что улучшает адгезию ее слоев. На первом этапе было проведено осаждение кадмиевой соли бегеновой кислоты. Осаждение проводилось при комнатной температуре и поверхностном давлении $30 \mathrm{MH} / \mathrm{M}$, слои матрицы осаждались по Ү-типу. Для изучения зависимости процессов формирования массивов НК от их поверхностной плотности были подготовлены образцы с толщиной исходной матрицы 2, 4, 8 и 20 монослоев (MC/ML). Осажденная на подложку ЛБ-матрица выдерживалась в атмосфере сероводорода при комнатной температуре и давлении 100 Торр в течение 3 ч. Как результат в ходе взаимодействия молекул сероводорода с бегенатом кадмия в матрице происходило образование $\mathrm{HK} \mathrm{CdS}$. На финальном этапе для удаления матрицы и пассивации НК осуществлялся отжиг образцов в атмосфере аммиака при температуре $200^{\circ} \mathrm{C}$ в течение 2 ч. Более детально процесс синтеза НК описан в ранее опубликованной работе [17]. Морфология образцов с НК исследовалась с помощью атомно-силового микроскопа (ACM) типа Solver P-47H (NT MDT).

\section{3. Экспериментальные результаты}

На рис. 1 приведены АСМ-изображения поверхности образцов с различной поверхностной плотностью НК. Как видно из рисунка, после отжига матрицы НК располагаются на поверхности ВОПГ в виде массивов, отдельные НК не встречаются. При низкой плотности (2 МС, рис. $1, a)$ НК собираются в небольшие массивы размерами около десятков и сотен нанометров. Мелкие массивы с характерным размером $<100$ нм имеют округлую форму или близкую к таковой, массивы покрупнее имеют более сложную форму, напоминающую фрактальную. При повышении поверхностной плотности НК (4 MC, рис. $1, b)$ массивы становятся более крупными и приобретают более разветвленную структуру, округлые массивы практически не встречаются. Структура массивов плотная, однако не может быть охарактеризована как плотноупакованная из-за большой дисперсии НК по размерам $(\sim 20 \%)$. При $8 \mathrm{MC}$ исходной матрицы (рис. 1,c) НК после отжига образуют структуру из соединенных друг с другом массивов, также имеющих фрактальную форму. При высокой плотности (20 MC, рис. $1, d)$ НК собираются в достаточно равномерный пористый субмонослой.

Большая часть массивов для всех представленных образцов имеет толщину около 3 нм, что соответствует диаметру НК, определенному ранее по данным сканирующей электронной микроскопии и спектрам фотолюминесценции, и указывает на то, что НК в массиве расположены в виде монослоя. Тем не менее некоторые массивы имеют бо́льшую высоту, указывающую на формирование второго слоя НК, доля таких массивов возрастает с повышением поверхностной плотности НК.

\section{4. Обсуждение результатов}

Изначально после этапа сульфидирования НК равномерно распределены в матрице и расположены по отдельности, что подтверждается проведенными ранее исследованиями методом просвечивающей электронной микроскопии высокого разрешения [18]. Следовательно, процесс объединения НК в массивы начинается и происходит исключительно на этапе отжига матрицы. Отправной точкой служит достижение матрицей температуры плавления, которая для бегеновой кислоты равняется $\sim 80^{\circ} \mathrm{C}$. После плавления матрицы НК начинают двигаться в ней и объединяться в массивы. Оценка энергии связи между НК ( 40 мэВ) в массиве, проведенная нами ранее, указывает на ван-дер-ваальсово взаимодействие между $\mathrm{HK} \mathrm{CdS}$ [15]. Квазидвумерная геометрия массивов свидетельствует о том, что процесс самосборки НК происходит главным образом в приповерхностной области подложки, и хорошо согласуется с тем фактом, что энергия связи НК с подложкой выше, чем энергия связи между НК. Отсутствие отдельных НК на поверхности подложки для образцов с низкой поверхностной плотностью НК свидетельствует о том, что НК в процессе самосборки имеют достаточно высокую подвижность и успевают собраться в массивы до окончания процесса испарения матрицы, когда процесс самосборки останавливается. Несмотря на то что форма массивов НК достаточно сложная и близка к фрактальной, наличие мелких округлых массивов при низких плотностях (2 МС) и формирование достаточно плотного субмонослоя при высоких (20 MC) свидетельствует о том, что НК достаточно 
$a$

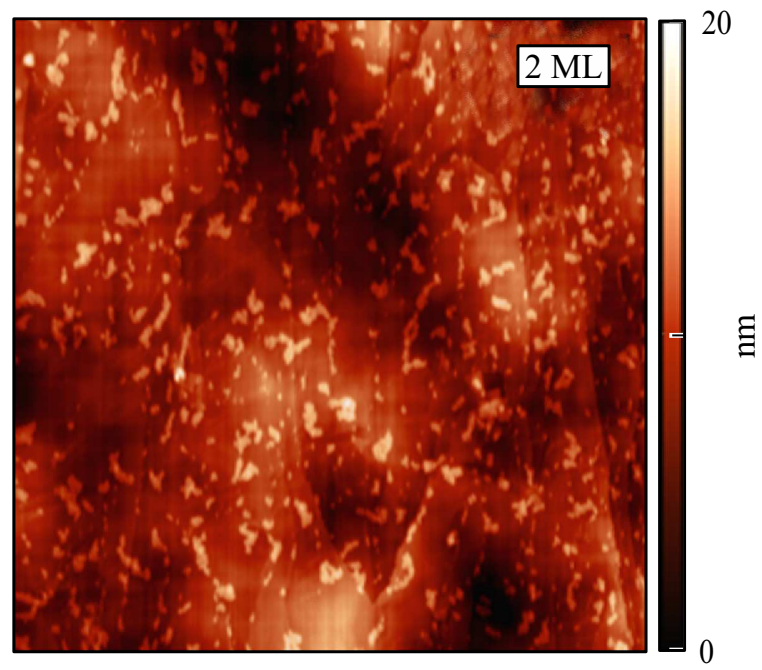

$c$

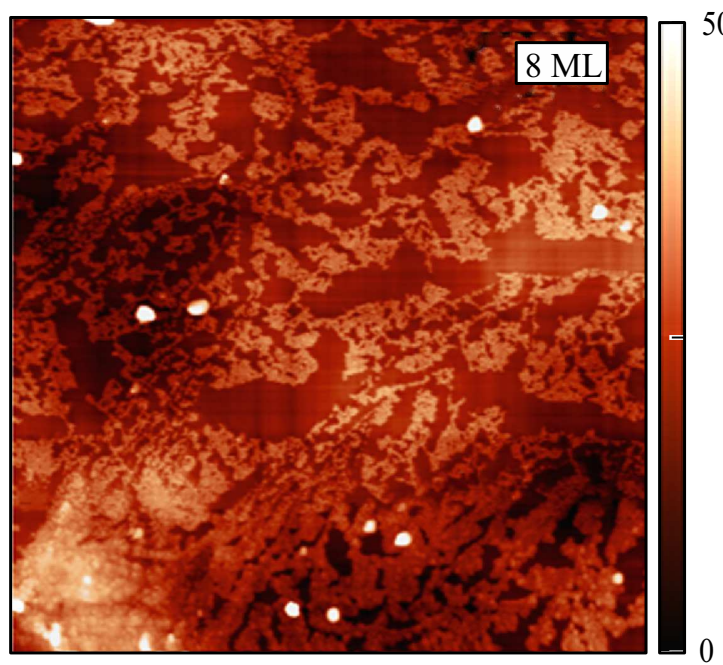

50

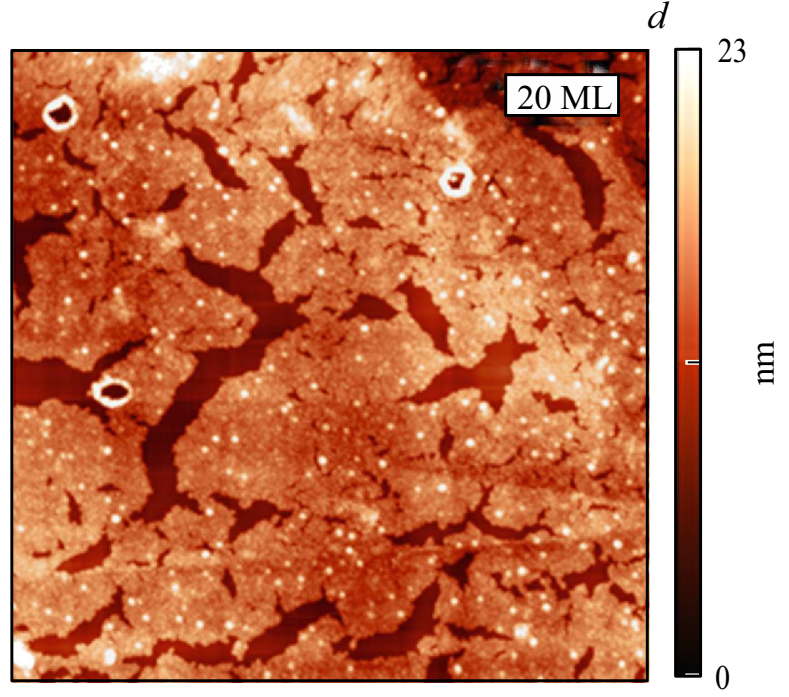

Рис. 1. Изображения поверхности ВОПГ после отжига матрицы с НК, полученные с помощью АСМ для образцов с толщиной исходной ЛБ-матрицы $2,4,8,20 \mathrm{MC}(a, b, c, d$ соответственно). Размер области сканирования $5 \times 5$ мкм для всех изображений. НК - более светлые области по сравнению с подложкой. Яркие (высокие) округлые образования связаны с частицами загрязнений, попавшими на образцы при отжиге, и не относятся к НК или остаткам матрицы.

подвижны и после объединения в массивы, т.е. могут двигаться друг относительно друга. Предельным случаем, при котором у агрегирующих частиц отсутствует возможность двигаться после присоединения к массиву, является модель диффузионно-ограниченной агрегации. В данном случае массивы формируют ярковыраженную фрактальную структуру броуновского дерева [19]. Как известно из теории агрегации НК, геометрия массивов при отсутствии ярковыраженных капиллярных эффектов определяется главным образом видом и величиной потенциала взаимодействия между НК [20]. Например, в случае стабилизированных органическими лигандами коллоидных НК, где взаимодействие между НК сравнительно слабое за счет действия стерических сил, самособранные массивы характеризуются гладкими кра- ями, округлыми формами и отсутствием выраженной фрактальной размерности [21]. Слабое взаимодействие обеспечивает высокую подвижность НК в составе массива, что позволяет рассматривать процесс самосборки коллоидных НК в массиве по аналогии с процессами разделения фаз в бинарных жидкостях [22]. В исследуемом случае морфология указывает на некий промежуточный механизм объединения НК. В нашем случае НК, как было установлено, притягиваются друг к другу за счет действия сил Ван-дер-Ваальса, в то же время природа сил отталкивания между НК однозначно не установлена. Так как при синтезе в ЛБ-матрице НК не имеют оболочки из органических лигандов, стерические силы, на первый взгляд, не могут быть причиной отталкивания НК. Кроме того, маловероятно образование двойного 


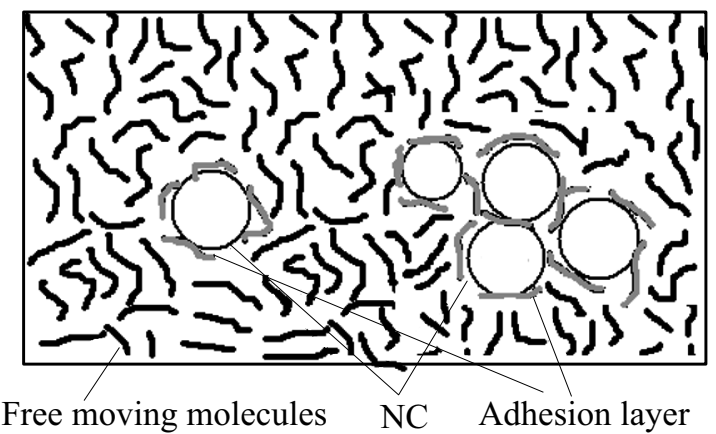

Рис. 2. Схематичное изображение взаимного расположения НК (NC), свободных молекул матрицы и адгезионного слоя из данных молекул.

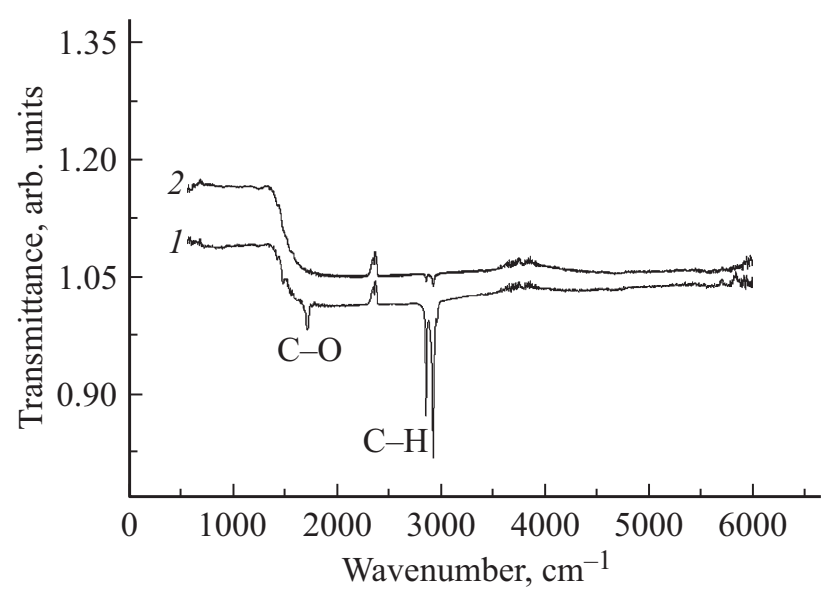

Рис. 3. ИК спектры образцов с $\mathrm{HK} \mathrm{CdS}$ до отжига (1) и после отжига матрицы (2). Спектры сдвинуты друг относительно друга по оси ординат для наглядности.

электрического слоя на поверхности НК при плавлении матрицы в силу низкой концентрации растворенных в ней ионов. На основании этого можно сделать вывод, что силы отталкивания между НК проявляются только при их тесном контакте и перекрытии электронных облаков соседних атомов. В таком случае, однако, при контакте НК из одного материала плоскостями с одной ориентацией может происходить их слипание в более крупные кристаллиты, чего не наблюдается в эксперименте. В случае слипания НК имели бы нулевую подвижность по краям кластера и формировали бы строго фрактальные структуры. Мы предполагаем, что двигающиеся НК окружены тонким (толщиной в одну молекулу) адсорбционным слоем молекул бегеновой кислоты или ее радикалов, образовавшихся при нагреве, который препятствует их слипанию (рис. 2). В таком случае НК после присоединения к массиву могут сохранять высокую подвижность и перестраиваться в составе массива в энергетически более выгодные положения, уплотняя его, что мы и видим из эксперимента.

Косвенным подтверждением наличия адсорбционного слоя органических остатков матрицы на поверхности
НК являются инфракрасные (ИК) спектры (рис. 3), полученные для образцов до и после отжига матрицы.

Из рис. 3 видно, что до отжига (кривая 1) присутствуют две области усиленного поглощения, а именно при значении волнового числа $1700 \mathrm{~cm}^{-1}$ и при значениях $2850,2900 \mathrm{~cm}^{-1}$, которые соответствуют поглощению на связях $\mathrm{C}-\mathrm{O}$ и $\mathrm{C}-\mathrm{H}$ соответственно. После отжига (кривая 2) поглощение на связях $\mathrm{C}-\mathrm{O}$ пропадает, однако поглощение на связях $\mathrm{C}-\mathrm{H}$ остается. Таким образом, даже после испарения органической матрицы до уровня, позволяющего разрешать массивы НК с помощью АСМ, ее остатки все еще присутствуют. Повышение температуры отжига до $250^{\circ} \mathrm{C}$ ведет к слипанию НК и образованию крупных кристаллитов, что, по-видимому,связано с удалением адсорбированных остатков матрицы.

Принимая во внимание вышесказанное, мы предлагаем следующее описание процесса образования массивов HK CdS при испарении матрицы ЛБ. На первоначальном этапе, непосредственно после плавления ЛБ-матрицы, НК начинают двигаться в ней и собираться в мелкие массивы. НК имеют достаточно высокую подвижность в объеме матрицы, а также имеют возможность перераспределяться в составе массива. Это ведет к тому, что мелкие массивы образуются достаточно быстро, а после образования стремятся приобрести сферическую форму, что наблюдается для преобладающего числа мелких массивов при низкой поверхностной плотности НК (2 МС). Образовавшиеся мелкие массивы НК начинают двигаться в приповерхностной области подложки и при сближении коалесцируют. Данный процесс начинает быть заметным уже при $2 \mathrm{MC}$ и проявляется в образовании крупных фрактальных массивов. Одновременно с процессом коалесценции массивов НК происходит процесс перехода НК в новые энергетически выгодные положения в массиве, что приводит к постепенному уплотнению структуры массивов. Далее все НК стремятся собраться в единый массив округлой формы, однако этого не происходит в силу конечного времени процесса испарения матрицы и достаточно малой скорости протекания коалесценции, которая к тому же замедляется при увеличении размеров массивов. Процессы коалесценции могут замедляться по ряду других причин. Одной из таких причин служит образование переходной сетчатой структуры из объединившихся массивов, что видно, например, при средних плотностях НК (8 МС). Данная структура похожа на гель и в литературе применительно к массивам нанокристаллов именуется „переходным гелем“ [23]. На этапе образования „переходного геля“ динамика процессов укрупнения массивов уже не описывается в рамках движения, столкновения и объединения массивов [24]. Это связано с тем, что массивы сцеплены друг с другом и их свободное движение требует разрыва множества связей НК друг с другом. Основным механизмом изменения морфологии гелей является их сморщивание, т. е. уплотнение структуры за счет сжатия, а также переход отдельных НК в более выгодные с точки 
зрения энергии положения. Несмотря на то что для образца с $8 \mathrm{MC}$ плотность НК на поверхности выше, чем для образцов с 2 и $4 \mathrm{MC}$, а время испарения матрицы больше, так как оно прямо пропорционально ее толщине, видно, что структура массивов при $8 \mathrm{MC}$ более рыхлая, что свидетельствует о формировании „переходного геля“ и замедлении процессов уплотнения структуры массивов. При $20 \mathrm{MC}$ за счет более чем двукратного увеличения поверхностной плотности НК и времени испарения матрицы наблюдается более плотная структура массива НК, он более похож на пористый субмонослой, который характерен для высокоподвижных коллоидных НК при высоких степенях покрытия. Тем не менее ряд характерных отличий свидетельствует о том, что наблюдаемая для $20 \mathrm{MC}$ структура является следствием уплотнения „переходного геля“ и не связана с процессами нуклеации и коалесценции пор в субмонослое, происходящими в коллоидных системах. Первым отличием служит геометрия пор, в случае нуклеации и коалесценции поры имеют округлую форму, а в нашем случае края пор достаточно грубые и угловатые. Вторым отличием служит наличие мелких узких пор, которые крайне невыгодны энергетически и в случае коллоидных растворов обычно связаны с тем, что на конечных этапах испарения растворителя силы взаимодействия между НК возрастают за счет уменьшения диэлектрической проницаемости окружения [25]. Характерным признаком трещин в данном случае является их направленность. Трещины перпендикулярны фронту испарения и направлены от краев массивов в глубь. Так как в нашем случае мелкие трещины не имеют характерной направленности, их наличие связано с незавершившимся процессом уплотнения гелевой структуры при сжатии.

\section{5. Заключение}

В настоящей работе изучена морфология самособранных на поверхности ВОПГ в процессе испарения органической матрицы Ленгмюра-Блоджетт HK CdS. Установлено, что в процессе испарения матрицы НК собираются в квазидвумерные массивы. В зависимости от толщины исходной ЛБ-матрицы, которая определяет итоговую поверхностную плотность НК, была обнаружена различная морфология самособранных массивов НК. При малых толщинах матрицы НК собираются в небольшие округлые массивы или массивы фрактальной формы, при средних толщинах НК образуют двумерную гелеобразную структуру, а при высоких толщинах матрицы - пористый субмонослой. Показано, что образование пористого субмонослоя является процессом сжатия гелеобразной структуры. Установлено, что НК имеют достаточно высокую подвижность в матрице расплавленной бегеновой кислоты, а также, несмотря на отсутствие оболочки из органических лигандов, достаточно подвижны и после присоединения к массивам, что позволяет формировать достаточно плотные структуры из НК, не характерные для нестабилизированных НК в растворах. Рассмотрены различные вероятные причины высокой подвижности НК в составе массива. В качестве объяснения предложено наличие адсорбционного слоя молекул матрицы на поверхности НК, который препятствует слипанию НК и создает отталкивающие силы между ними при сильном сближении. Предположение о наличии адсорбционного слоя косвенно подтверждается экспериментальными данными ИК спектроскопии.

\section{Финансирование работы}

Работа выполнена при финансовой поддержке Российского научного фонда в рамках проекта № 18-72-00027.

\section{Конфликт интересов}

Авторы заявляют, что у них нет конфликта интересов.

\section{Список литературы}

[1] A.M. Smith, S. Nie. Acc. Chem. Res., 43 (2), 190 (2010).

[2] C. Tablero. J. Appl. Phys., 106, 074306 (2009).

[3] F. Xu, L.F. Gerlein, X. Ma, C.R. Haughn, M.F. Doty, S.G. Cloutier. Materials, 8 (4), 1858 (2015)

[4] D. Bera, L. Qian, T.-K. Tseng, P.H. Holloway. Materials, 3 (4), 2260 (2010).

[5] S. Wang, C. Querner, T. Dadosh, C.H. Crouch, D.S. Novikov, M. Drndic. Nature Commun., 2, 364 (2011).

[6] M.A. Boles, M. Engel, D.V. Talapin. Chem. Rev., 116 (18), 11220 (2016).

[7] N. Vogel, M. Retsch, C.A. Fustin, A. Campo, U. Jonas. Chem. Rev., 115 (13), 6265 (2015).

[8] Q. Li, U. Jonas, X.S. Zhao, M. Kappl. Asia-Pacific J. Chem. Eng., 3 (3), 255 (2008).

[9] P.A. Kralchevsky, K. Nagayama. Langmuir, 10 (1), 23 (1994).

[10] C. Delerue. Nature Materials, 15, 498 (2016).

[11] G. Zotti, B. Vercelli, A. Berlin, M. Pasini, T.L. Nelson, R.D. McCulough, T. Virgili. Chem. Mater., 22 (4), 1521 (2010).

[12] D.K. Smith, B. Goodfellow, D.-M. Smilgies, B.A. Korgel. J. Am. Chem. Soc., 131 (9), 3281 (2009).

[13] M.P. Pileni. J. Phys. Chem. B, 105 (17), 3358 (2001).

[14] Е.А. Багаев, К.С. Журавлев, Л.Л. Свешникова, И.А. Бадмаева, С.М. Репинский, М. Воелсков. ФТП, 37 (11), 1358 (2003).

[15] D.Yu. Protasov, W.-B. Jian, K.A. Svit, T.A. Duda, S.A. Teys, A.S. Kozhuhov, L.L. Sveshnikova, K.S. Zhuravlev. J. Phys. Chem. C, 115 (41), 20148 (2011).

[16] K.A. Svit, D.Yu. Protasov, S.A. Teys, L.L. Sveshnikova, M.V. Yakushev, K.S. Zhuravlev. Phys. Status Solidi C, 13 (7), 417 (2015).

[17] A.G. Milekhin, L.L. Sveshnikova, S.M. Repinskii, A.K. Gutakovskii, M. Friedrich, D.R.T. Zahn. Phys. Solid State, 44, 1976 (2002).

[18] S.A. Batsanov, A.K. Gutakovskii. Nanotechnol. Russ., 12 (7), 369 (2017).

[19] L. Qiao, M.T. Swihart. Adv. Colloid Interface. Sci., 244, 199 (2017). 
[20] M.A. Boles, M. Engel, D.V. Talapin. Chem. Rev., 116, 11220 (2016).

[21] E. Rabani, D.R. Reichman, P.L. Geissler, L.E. Brus. Nature, 426 (6964), 271 (2003).

[22] J. Tang, G. Ge, L.E. Brus. J. Phys. Chem. B, 106, 5653 (2002).

[23] E. Zaccareli. J. Phys. Condens. Matter, 19, 323101 (2007).

[24] H. Tanaka. J. Phys. Condens. Matter, 12, R207 (2000).

[25] G. Ge. L. Brus. J. Phys. Chem. B, 104 (41), 9573 (2000).

Редактор Л.В. Шаронова

\title{
Self-assembly processes of arrays of CdS nanocrystals obtained by Langmuir-Blodgett technique
}

\author{
K.A. Svit ${ }^{1}$, K.S. Zhuravlev ${ }^{1,2}$ \\ ${ }^{1}$ Rzhanov Institute of Semiconductor Physics, \\ Siberian Branch of Russian Academy of Sciences, \\ 630090 Novosibirsk, Russia \\ ${ }^{2}$ Novosibirsk State University, \\ 630090 Novosibirsk, Russia
}

Abstract The morphology of CdS nanocrystal arrays selfassembled during the evaporation of behenic acid organic matrix on the surface of a wetted substrate was studied by atomic force microscopy. The dependence of the nanocrystal arrays morphology on the original matrix thickness was studied. The nanocrystal arrays morphology varied noticeably from small fractal arrays to a porous submonolayer as the nanocrystal density increased. The nature of repulsive forces between the nanocrystals which prevented their irreversible adhesion and ensures their relatively high mobility within the arrays has been proposed. 